\title{
Mangiferin activates Nrf2-antioxidant response element signaling without reducing the sensitivity to etoposide of human myeloid leukemia cells in vitro
}

\author{
Ben-ping ZHANG ${ }^{1, \#}$, Jie ZHAO ${ }^{1, \#}$, Shan-shan $\mathrm{LI}^{1}$, Li-jing YANG ${ }^{1}$, Ling-lan ZENG ${ }^{2}$, Yan CHEN ${ }^{1, *}$, Jun FANG ${ }^{1, *}$ \\ ${ }^{1}$ Department of Hematology, Union Hospital, Tongji Medical College, Huazhong University of Science and Technology, Wuhan 430022, \\ China; ${ }^{2}$ Department of Central Laboratory, Union Hospital, Tongji Medical College, Huazhong University of Science and Technology, \\ Wuhan 430022, China
}

\begin{abstract}
Aim: Mangiferin is glucosylxanthone extracted from plants of the Anacardiaceae and Gentianaceae families. The aim of this study was to investigate the effects of mangiferin on Nrf2-antioxidant response element (ARE) signaling and the sensitivity to etoposide of human myeloid leukemia cells in vitro.

Methods: Human HL-60 myeloid leukemia cells and mononuclear human umbilical cord blood cells (MNCs) were examined. Nrf2 protein was detected using immunofluorescence staining and Western blotting. Binding of Nrf2 to ARE was examined with electrophoretic mobility shift assay. The level of NQO1 was assessed with real-time RT-PCR and Western blotting. DCFH-DA was used to evaluate intracellular ROS level. Cell proliferation and apoptosis were analyzed using MTT and flow cytometry, respectively. Results: Mangiferin (50 $\mu \mathrm{mol} / \mathrm{L})$ significantly increased Nrf2 protein accumulation in HL-60 cells, particularly in the nucleus. Mangiferin also enhanced the binding of Nrf2 to an ARE, significantly up-regulated NQO1 expression and reduced intracellular ROS in HL60 cells. Mangiferin alone dose-dependently inhibited the proliferation of HL-60 cells. Mangiferin ( $50 \mathrm{~mol} / \mathrm{L})$ did not attenuate etoposide-induced cytotoxicity in $\mathrm{HL}-60$ cells, and combined treatment of mangiferin with low concentration of etoposide $(0.8 \mu \mathrm{g} / \mathrm{mL})$ even increased the cell inhibition rate. Nor did mangiferin change the rate of etoposide-induced apoptosis in HL-60 cells. In MNCs, mangiferin significantly relieved oxidative stress, but attenuated etoposide-induced cytotoxicity.

Conclusion: Mangiferin is a novel Nrf2 activator that reduces oxidative stress and protects normal cells without reducing the sensitivity to etoposide of HL-60 leukemia cells in vitro. Mangiferin may be a potential chemotherapy adjuvant.
\end{abstract}

Keywords: leukemia; chemotherapy; drug resistance; oxidative stress; Nrf2; antioxidant response element; mangiferin; etoposide

Acta Pharmacologica Sinica (2014) 35: 257-266; doi: 10.1038/aps.2013.165; published online 30 Dec 2013

\section{Introduction}

More than $40 \%$ of the anticancer drugs approved by the US Food and Drug Administration (FDA) have been reported to induce oxidative stress, which is a mechanism for killing cancer cells. However, anticancer drugs can also cause oxidative stress-mediated non-target tissue injury, which is a significant side effect of chemotherapy and decreases the quality of life in patients ${ }^{[1]}$. Moreover, certain widely used and effective anticancer drugs, particularly alkylating agents and topoisomerase II inhibitors, can also induce oxidative DNA damage, which has been proven to be associated with the development

\footnotetext{
\# These authors contributed equally to this work.

* To whom correspondence should be addressed.

E-mail junfang@mail.hust.edu.cn (Jun FANG); yanchen@public.wh.hb.cn (Yan CHEN)

Received 2013-07-12 Accepted 2013-10-02
}

of secondary malignancies, including acute myeloid leukemia $(\mathrm{AML})^{[2,3]}$. Therefore, reducing anticancer drug-induced oxidative stress may contribute to relieving side effects and preventing the formation of chemotherapy-associated secondary malignancies.

A major mechanism of the cellular defense against oxidative stress is the activation of NF-E2-related nuclear factor 2 (Nrf2)-antioxidant response element (ARE) signaling, which controls the expression of many detoxification and antioxidant enzymes, including $\mathrm{NAD}(\mathrm{P}) \mathrm{H}$ :quinone oxidoreductase 1 (NQO1 $^{[4-6]}$. It has been well established that Nrf2 activity is controlled in part by the cytosolic protein Kelch-like ECHassociated protein 1 (Keap1), a known repressor of Nrf2. However, the mechanisms by which Keap1 acts to repress Nrf2 activity are not fully understood. A number of studies recently corroborated that Keap1 represses Nrf2 activity by 
promoting its ubiquitylation and degradation in non-stressed cells. In contrast, increased Nrf2 stability results in the accumulation of Nrf2 protein and subsequent activation of Nrf2ARE signaling in stressed cells ${ }^{[4]}$. In addition to oxidative stress, it had been reported that certain types of synthetic and natural chemicals, including tert-butylhydroquinone (t-BHQ), $3 H$-1,2-dithiole-3-thione (D3T), oridonin, and ajoene ${ }^{[7-10]}$, can activate Nrf2-ARE signaling by increasing the stability of the Nrf2 protein.

Recent studies have suggested that the activation of Nrf2ARE signaling can confer protection to normal cells or tissues against anticancer drugs. Eriodictyol-7-O-glucoside, a flavonoid isolated from Dracocephalum rupestre, has been reported to activate the Nrf2 signaling pathway and significantly decrease cisplatin-induced toxicity in the human renal mesangial cell (HRMC) line ${ }^{[11]}$. In vitro and animal experiments have also demonstrated that ebselen activates the Nrf2-ARE signaling pathway, ultimately preventing free radical stress due to cisplatin and protecting auditory sensory hair cells ${ }^{[12]}$. In an animal model of adriamycin-induced cardiac fibrosis, 3,3'-diindolymethane both activated Nrf2 in cardiac tissue and fibroblasts and exhibited a significant anti-fibrosis effect on cardiac tissue ${ }^{[13]}$. Nrf2-ARE signaling has also been identified as a potential target for inflammation-associated and chemical-induced carcinogenesis ${ }^{[14,15]}$. However, Nrf2 also has a "dark side": the activation of Nrf2 by chemical compounds or an Nrf2 expression plasmid enhances the resistance of cancer cells to chemotherapeutic agents, whereas Nrf2 silencing increases the sensitivity of cancer cells to chemotherapy ${ }^{[16-19]}$. Therefore, Nrf2 comprises an attractive target for preventing chemotherapy-associated side effects in normal cells and also a potentially powerful partner in cancer cells.

Mangiferin, 1,3,6,7-tetrahydroxyxanthone-C2-beta-d-glucoside, a type of xanthone derivative and C-glucosylxanthone, is a monomer compound extracted from plants of the Anacardiaceae and Gentianaceae families ${ }^{[20]}$. This natural compound has strong antiradical and antioxidant properties and also exhibits cardio-, hepato-, and neuroprotective activities in addition to a radioprotective activity ${ }^{[21]}$. Here, we demonstrate that mangiferin activated Nrf2-ARE signaling but did not increase the resistance to anticancer drugs in human HL-60 myeloid leukemia cells; therefore, mangiferin is a novel Nrf2 activator without a "dark side".

\section{Materials and methods Cell lines and reagents}

The human HL-60 myeloid leukemia cell line was kindly provided by Prof Jian-feng ZHOU (Cancer Biology Research Center, Tongji Hospital, Wuhan, China) and maintained in RPMI1640 medium (Hyclone, Logan, UT, USA) supplemented with $10 \%$ fetal bovine serum (Hyclone, Logan, UT, USA) at $37^{\circ} \mathrm{C}$ in a humidified incubator containing $5 \% \mathrm{CO}_{2}$ in air.

Mangiferin (98\% purity), dimethylsulfoxide (DMSO), 3-(4,5-dimethylthiazol-2-yl)-2,5-diphenyltetrazolium bromide (MTT), and Hoechst 33258 were purchased from Sigma-Aldrich (St Louis, MO, USA). Etoposide injection was obtained from
Jiangsu Hengrui Medicine (Lianyungang, China). Mangiferin was initially dissolved in DMSO, stored at $-20^{\circ} \mathrm{C}$, and then thawed on ice prior to use.

\section{Isolation and culture of mononuclear human umbilical cord} blood cells

Samples of human umbilical cord blood (hUCB) were obtained, with informed consent, during normal full-term deliveries, a procedure that was approved by the Institutional Ethics Review Committee of Tongji Medical College, Huazhong University of Science and Technology. After removing the erythrocytes by using 6\% hydroxyethyl starch, the mononuclear cells (MNCs) were isolated by Ficoll-Paque density gradient centrifugation. hUCB MNCs were cultured in a serum-free medium for hematopoietic stem cells (Gibco, Grand Island, NY, USA) supplemented with $2 \mathrm{mmol} / \mathrm{L}$ L-glutamine, $100 \mathrm{U} / \mathrm{mL}$ penicillin, and $100 \mathrm{mg} / \mathrm{mL}$ streptomycin in a humidified incubator containing $5 \% \mathrm{CO}_{2}$ at $37^{\circ} \mathrm{C}$.

\section{Immunofluorescence staining}

HL-60 cells were seeded in a 6 -well plate $\left(1 \times 10^{6}\right.$ per well $)$ and incubated at $37^{\circ} \mathrm{C}$ for $24 \mathrm{~h}$. The cells were then incubated with $50 \mu \mathrm{mol} / \mathrm{L}$ mangiferin for $15 \mathrm{~min}, 1 \mathrm{~h}, 4 \mathrm{~h}$, or $24 \mathrm{~h}$, fixed with $4 \%$ paraformaldehyde, and carefully seeded on poly-Llysine-coated coverslips. The cells were permeabilized with $0.3 \%$ Triton $X-100$, blocked with $3 \%$ bovine serum albumin, and incubated with an anti-Nrf2 antibody (dilution of 1:100, Santa Cruz, TX, USA) overnight at $4{ }^{\circ} \mathrm{C}$. The cells were then incubated with a fluorescein isothiocyanate (FITC)-conjugated goat-anti-rabbit antibody (Pierce, Rockford, IL, USA), and the nuclei were stained with Hoechst 33258. Confocal microscopy was performed, and images were captured using an Olympus IX71 laser-scanning confocal microscope system (Olympus, Tokyo, Japan) fitted with an AxioCam MRc color CCD (Zeiss, Thuringia, Germany). The images were analyzed using Olympus Fluoview Version 4.3 FV500 Tiempo software. Control cells were processed identically except omitting the mangiferin treatment.

\section{Western blot}

HL-60 cells were seeded in a 6 -well plate $\left(2 \times 10^{6}\right.$ per well $)$ and incubated at $37^{\circ} \mathrm{C}$ for $24 \mathrm{~h}$. In time-response experiments, the cells were treated with $50 \mu \mathrm{mol} / \mathrm{L}$ mangiferin for 1 , 4, or $24 \mathrm{~h}$; in dose-response experiments, the cells were incubated with 50,100 , or $200 \mu \mathrm{mol} / \mathrm{L}$ mangiferin for $24 \mathrm{~h}$. The cells were lysed, and the supernatants were collected after centrifugation at $15000 \mathrm{r} / \mathrm{min}$ for $10 \mathrm{~min}$ at $4^{\circ} \mathrm{C}$. The protein concentrations were determined using a BCA protein assay kit (Pierce, Rockford, IL, USA). To explore whether Nrf2 in the nucleus increased after mangiferin treatment, HL-60 cells were seeded in a 6 -well plate $\left(2 \times 10^{6}\right.$ per well $)$ and treated with $50 \mu \mathrm{mol} / \mathrm{L}$ mangiferin for $4 \mathrm{~h}$. The proteins in the cytoplasm and nucleus were extracted using a Nuclear Extract Popper kit (Pierce, Rockford, IL, USA). After denaturation, equal amounts of the protein extracts were separated by SDS-PAGE, followed by transfer onto a polyvinylidene difluoride (PVDF) membrane. 
The membrane was blocked in phosphate-buffered saline (PBS) containing 5\% non-fat milk for $1 \mathrm{~h}$ at room temperature. The blots were subsequently incubated with an anti-Nrf2 antibody or anti-NOQ1 antibody (SantaCruz, TX, USA) for $24 \mathrm{~h}$ at $4^{\circ} \mathrm{C}$, followed by washes and incubation with an HRP-labeled secondary antibody (Pierce, Rockford, IL, USA) for $2 \mathrm{~h}$ at room temperature. The blots were then incubated with an enhanced chemiluminescence (ECL) solution for $5 \mathrm{~min}$, and the signals were detected using a chemiluminescence detection system (Bio-Rad, Hercules, CA, USA) or photographic film (Kodak, Rochester, NY, USA). Control cells were processed identically except omitting the mangiferin treatment.

\section{Electrophoretic mobility shift assay (EMSA)}

HL-60 cells were seeded in a 6-well plate $\left(2 \times 10^{6}\right.$ per well $)$ and treated with $50 \mu \mathrm{mol} / \mathrm{L}$ mangiferin for $4 \mathrm{~h}$; control cells were processed identically except omitting the mangiferin treatment. Nuclear extracts were then prepared using a Nuclear Extract Popper kit (Pierce, Rockford, IL, USA). EMSA was performed using ARE consensus oligonucleotides (Beyotime Institute Biotechnology, Shanghai, China) end-labeled with biotin or not with biotin. The sequences of the doublestranded ARE oligonucleotides were as follows: 5'-ACT GAG GGT GAC TCA GCA AAA TC-3' and 3'-TGA CTC CCA CTG AGT CGT TTT AG-5'. The EMSA experiments were performed using $6 \%$ polyacrylamide gels in Tris-borate-EDTA buffer (45 mmol/L Tris-borate/1 mmol/L EDTA). Each EMSA reaction mixture contained $500 \mathrm{ng}$ of poly(dI-dC), $1 \times$ LightShift EMSA kit binding buffer (Pierce, Rockford, IL, USA), $1 \times$ LightShift loading dye (Pierce, Rockford, IL, USA), an appropriate amount of DNA probe, and the protein preparation. A competition reaction was performed with a 200 -fold excess of unlabeled probe. The EMSA gels were electroblotted onto nylon membranes, and the signals were detected using the LightShift Chemiluminescent EMSA kit (Pierce, Rockford, IL, USA) and BioMax film (Kodak, Rochester, NY, USA).

\section{Real-time reverse transcription-polymerase chain reaction (real- time RT-PCR)}

HL-60 cells were seeded in a 6 -well plate $\left(1 \times 10^{6}\right.$ per well $)$ and incubated at $37^{\circ} \mathrm{C}$ for $24 \mathrm{~h}$. For the time-response experiments, the cells were treated with $50 \mu \mathrm{mol} / \mathrm{L}$ mangiferin for $12 \mathrm{~h}$ or $24 \mathrm{~h}$, and the cells were incubated with $50 \mu \mathrm{mol} / \mathrm{L}$ or $100 \mu \mathrm{mol} / \mathrm{L}$ mangiferin for $24 \mathrm{~h}$ for the dose-response experiments. Total RNA was isolated using RNAiso Plus (Takara Bio, Shiga, Japan), and 400 ng total RNA was reverse transcribed into cDNA using a one-step RT-PCR kit (Takara Bio, Shiga, Japan) according to the manufacturer's instructions. cDNA $(2 \mu \mathrm{L})$ was amplified with the SYBR Green Universal PCR Master mix (Takara Bio, Shiga, Japan) in triplicate using a Real-time PCR System (Bio-Rad CFX96, Hercules, CA, USA). The NQO1 mRNA levels, as related to $\beta$-actin, were calculated using the Delta Ct (cycle threshold) method. The primers for real-time RT-PCR were designed and synthesized by Takara Bio (Shiga, Japan). Control cells were processed identically except omitting the mangiferin treatment.

\section{Measurement of intracellular reactive oxygen species (ROS) production}

To further investigate whether mangiferin relieved oxidative stress in HL-60 cells, the production of ROS was measured using 2,7-dichlorodihydrofluorescein diacetate (DCFH-DA), a sensitive fluorescent probe for ROS detection. When DCFHDA enters a cell, it is deacetylated by esterases to generate DCFH; DCFH then can be oxidized by ROS to produce highly fluorescent $2^{\prime}, 7^{\prime}$-dichlorofluorescein $(\mathrm{DCF})^{[22]}$. The HL-60 cells were seeded in a 6 -well plate $\left(5 \times 10^{5}\right.$ per well), pre-incubated with or without $50 \mu \mathrm{mol} / \mathrm{L}$ mangiferin for $4 \mathrm{~h}$, and treated with or without $20 \mu \mathrm{g} / \mathrm{mL}$ etoposide for $8 \mathrm{~h}$. HL-60 cells without added mangiferin or etoposide served as the control. The cells were then treated with $20 \mu \mathrm{mol} / \mathrm{L}$ DCFH-DA for 20 min at $37^{\circ} \mathrm{C}$, harvested, washed with PBS 5 times, and viewed under a fluorescence microscope (TE2000-S, Nikon, Japan). The integral optical density (IOD) was detected using Image Pro Plus (IPP) software.

We next explored whether mangiferin could relieve the oxidative stress in hUCB MNCs. The cells were seeded in a 24 -well plate $\left(5 \times 10^{5}\right.$ per well) and then treated as mentioned above for HL-60 cells. The cells were then harvested, washed with PBS 5 times, and viewed under a fluorescence microscope (TE2000-S, Nikon, Japan). IOD was detected using IPP software.

\section{Cell proliferation assay}

HL-60 cells were seeded in a 96 -well plate $\left(5 \times 10^{3}\right.$ per well $)$ and incubated at $37^{\circ} \mathrm{C}$ for $24 \mathrm{~h}$. For the etoposide dose-response experiments, the cells were pre-incubated with or without 50 $\mu \mathrm{mol} / \mathrm{L}$ mangiferin for $4 \mathrm{~h}$ and then treated with $0.8,4,20$, 100 , or $500 \mu \mathrm{g} / \mathrm{mL}$ etoposide at $37^{\circ} \mathrm{C}$ for $24 \mathrm{~h}$. For the mangiferin dose-response experiments, the cells were pre-incubated with $50 \mu \mathrm{mol} / \mathrm{L}$ or $100 \mu \mathrm{mol} / \mathrm{L}$ mangiferin for $4 \mathrm{~h}$ and then treated with $10 \mu \mathrm{g} / \mathrm{mL}$ etoposide at $37^{\circ} \mathrm{C}$ for $24 \mathrm{~h}$. In addition, we explored the cytotoxicity effect of a single mangiferin treatment in HL-60 cells, which were seeded and incubated as above and then treated with mangiferin $(0,50,100,200$, or $400 \mu \mathrm{mol} / \mathrm{L})$ for $24 \mathrm{~h}$.

To examine whether mangiferin could relieve etoposideinduced cytotoxicity in normal hematopoietic cells, hUCB MNCs were seeded in a 96 -well plate $\left(1.0 \times 10^{4}\right.$ per well), preincubated with or without $50 \mu \mathrm{mol} / \mathrm{L}$ mangiferin for $4 \mathrm{~h}$, and treated with or without $20 \mu \mathrm{g} / \mathrm{mL}$ etoposide for $8 \mathrm{~h}$. hUCB MNCs without added mangiferin or etoposide served as the control.

After the treatment, the plates were centrifuged at 2000 $\mathrm{r} / \mathrm{min}$ for $20 \mathrm{~min}$, the culture supernatant was removed, and the cells were washed twice with culture medium. The cells were then incubated with $5 \mathrm{mg} / \mathrm{mL}$ MTT (20 $\mu \mathrm{L}$ per well) at $37^{\circ} \mathrm{C}$ for $4 \mathrm{~h}$, and the supernatants were carefully removed after the plates were centrifuged. Lastly, DMSO was added $(150 \mu \mathrm{L}$ per well), and the optical density (OD) values were measured. The cell viability of hUCB MNCs was normalized to an untreated sample. The inhibition rate of the HL-60 cells 
was calculated using the following formula: cell proliferation inhibition rate $(\%)=[1-(\mathrm{OD}$ of the experimental sample $/ \mathrm{OD}$ of the control sample) $] \times 100 \%$. The $\mathrm{IC}_{50}$ value was taken as the concentration that caused $50 \%$ inhibition of cell proliferation.

\section{Flow cytometry analysis}

HL-60 cells were seeded in a 6-well plate $\left(1 \times 10^{6}\right.$ per well $)$ in the presence or absence of $50 \mu \mathrm{mol} / \mathrm{L}$ mangiferin. After $4 \mathrm{~h}$, the cells were treated with $1 \mu \mathrm{g} / \mathrm{mL}$ or $2 \mu \mathrm{g} / \mathrm{mL}$ etoposide at $37^{\circ} \mathrm{C}$ for $24 \mathrm{~h}$. The cells were then harvested and washed twice with cold PBS. Apoptotic cells were stained with an AnnexinV-FITC/PI double-staining assay kit (KeyGEN Biotec, Jiamgsu, China) and analyzed by flow cytometry (BD LSR II, Franklin Lakes, NJ, USA). The apoptosis rate was calculated as AnnexinV-positive cells/total cells $\times 100 \%$.

\section{Statistics}

The results are expressed as the mean value $\pm \mathrm{SD}$ of three independent experiments. A two-tailed Student's $t$-test was used to determine the significance of the differences, and a difference was considered statistically significant when $P<0.05$. The $\mathrm{IC}_{50}$ value was obtained with SPSS 17.0.

\section{Results \\ Mangiferin increased the accumulation of Nrf2 protein in HL-60 cells}

To explore whether mangiferin activates Nrf2-ARE signaling in HL-60 cells, the accumulation of Nrf2 protein was examined by immunofluorescence staining and Western blotting. As shown in Figure 1A, immunofluorescence staining results demonstrated that the Nrf2 protein was located both in the nucleus and cytoplasm of non-treated cells. However, the Nrf2 protein concentration appeared to be higher in the cytoplasm than the nucleus, as the cytoplasmic green fluorescence (indicating Nrf2) was stronger in most cells. Both the nuclear and global Nrf2 protein levels increased in a time-dependent manner after mangiferin treatment. Consistent with the immunofluorescence staining results, the Western blot results (Figure 1B and 1C) also revealed that mangiferin enhanced the whole-cell accumulation of Nrf2 protein in a time-dependent and dose-dependent manner. As shown in Figure 1D1 and 1D2, Nrf2 protein in the cytoplasm increased after mangiferin treatment, though the difference was not significant; in contrast, mangiferin significantly increased the Nrf2 protein level in the nucleus compared to the non-treated cells. These results indicated that mangiferin enhanced the accumulation of Nrf2 protein in HL-60 cells, particularly in the nucleus.

\section{Nrf2 protein from mangiferin-treated HL-60 cells showed increased ARE binding}

The EMSA results shown in Figure 2 demonstrated that the complex of human NQO1 ARE DNA with Nrf2 protein increased after mangiferin treatment (lane 2, compared to lane 1). To test the specificity of Nrf2 binding to the human NQO1 ARE-containing DNA probe, a competition assay was performed with a 200-fold excess of unlabeled probe, nearly abolishing the formation of the DNA-protein complex (lanes 3 , compared to lane 2). These data indicated that mangiferin treatment of HL-60 cells enhanced the binding of the Nrf2 protein to an ARE DNA sequence.

\section{Mangiferin upregulated NQ01 expression in HL-60 cells}

NQO1, a downstream protein of Nrf2-ARE signaling, is one of the most important intracellular detoxification and antioxidant enzymes. Western blotting and real-time RT-PCR analyses were performed to detect the NQO1 protein and mRNA levels after mangiferin treatment. The real-time RT-PCR results showed that mangiferin treatment significantly enhanced NQO1 transcription in time- and dose-dependent manners in HL-60 cells, as shown in Figure 3A and 3B. Consistent with these results, the Western blot results also demonstrated the up-regulation of NQO1 expression by mangiferin in time- and dose-dependent manners, as shown in Figure 3C and 3D.

\section{Mangiferin relieved oxidative stress in HL-60 cells}

The effect of mangiferin treatment on intracellular oxidative stress was examined by DCFH-DA, a sensitive fluorescent probe for ROS detection. As shown in Figure 4, etoposide stimulation increased intracellular ROS in HL-60 cells compared to the control. However, when the HL-60 cells were pre-incubated with mangiferin prior to etoposide incubation, intracellular ROS levels were lower than in the cells incubated with etoposide alone. Intracellular ROS levels were also significantly lower in HL-60 cells treated with mangiferin alone than in the cells without any treatment.

\section{Mangiferin did not reduce the cytotoxicity of etoposide in HL-60 cells}

As shown in Figure 5A, when HL-60 cells were exposed to $0.8,4,20,100$, and $500 \mu \mathrm{g} / \mathrm{mL}$ etoposide for $24 \mathrm{~h}$, the cell inhibition rates were $12.63 \% \pm 1.3 \%, 61.8 \% \pm 0.78 \%, 63.4 \% \pm 1.5 \%$, $76.2 \% \pm 2.5 \%$, and $99.2 \% \pm 0.2 \%$, respectively, and the $\mathrm{IC}_{50}$ value was $6.32 \mu \mathrm{g} / \mathrm{mL}$. However, when the cells were pre-incubated with $50 \mu \mathrm{mol} / \mathrm{L}$ mangiferin for $4 \mathrm{~h}$ prior to etoposide treatment, the cell inhibition rates were $17.0 \% \pm 0.4 \%, 61.6 \% \pm 2.6 \%$, $67.2 \% \pm 4.1 \%, 77.2 \% \pm 2.2 \%$, and $99.1 \% \pm 0.3 \% \quad(P=0.0052,0.9185$, $0.2033,0.6164$, and 0.6095 compared to the cells treated with etoposide alone), respectively, and the $\mathrm{IC}_{50}$ value became $5.20 \mu \mathrm{g} / \mathrm{mL}$. When the HL-60 cells were pre-incubated with 0,50 , and $100 \mu \mathrm{mol} / \mathrm{L}$ mangiferin for $4 \mathrm{~h}$ and then treated with $10 \mu \mathrm{g} / \mathrm{mL}$ etoposide for $24 \mathrm{~h}$, the cell inhibition rates were $84.2 \% \pm 3.3 \%, 84.2 \% \pm 1.7 \%$, and $82.1 \% \pm 3.0 \%$, respectively (Figure 5B). However, compared to the single-agent etoposide treatment, the cell inhibition rates were not significantly different when the cells were pre-incubated with mangiferin $(P=0.9824$ and 0.4449 , respectively). As shown in Figure 5C, a single treatment of mangiferin also inhibited the proliferation of HL-60 cells in time- and dose-dependent manners.

Mangiferin did not decrease etoposide-induced apoptosis in HL60 cells

As shown in Figure 6, the apoptotic rates were 15.23\% $\pm 7.96 \%$ 
A

$\mathrm{MA}(50 \mu \mathrm{mol} / \mathrm{L})$
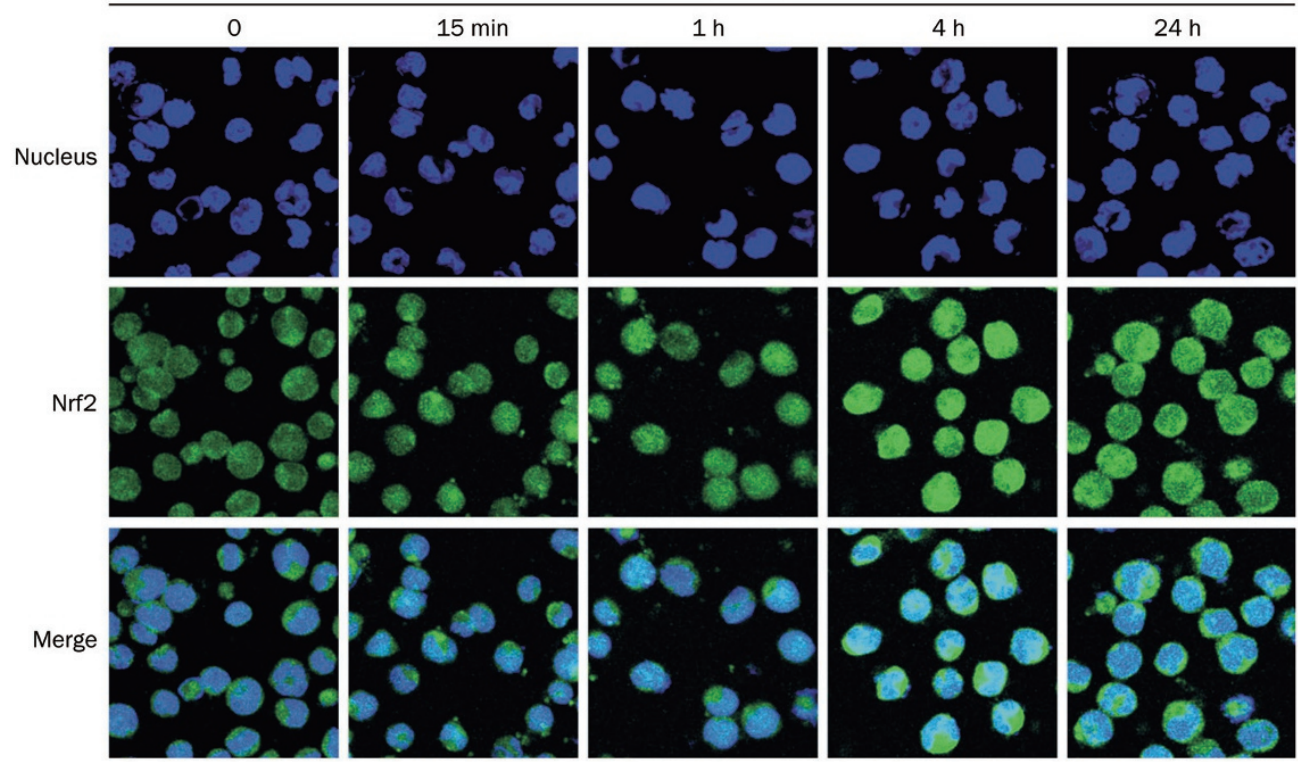

B

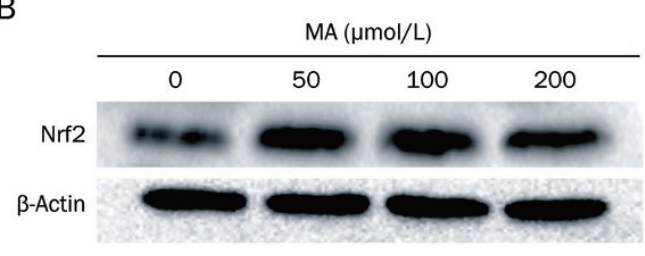

C

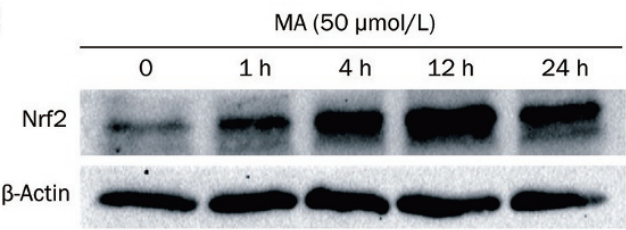

D1
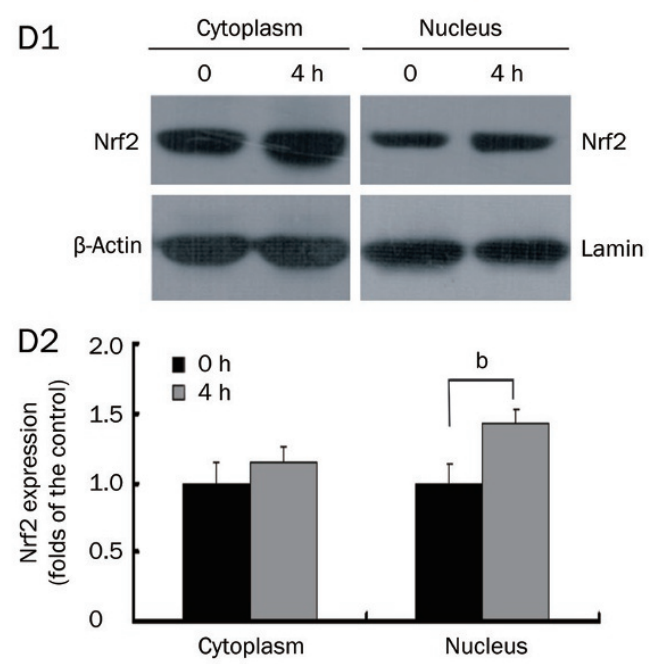

Figure 1. Mangiferin (MA) increased accumulation of Nrf2 protein in HL-60 cells. (A) HL-60 cells were incubated with $50 \mu \mathrm{mol} / \mathrm{L}$ mangiferin for 15 min, 1, 4, or $24 \mathrm{~h}$. Subcellular localization of Nrf2 protein was determined by confocal microscopy using FITC-conjugated Nrf2 antibody (green color). Nuclei were visualized by Hoechst staining (blue color). Merging Nrf2 and nuclei images (cyan color) confirmed nuclear localization of Nrf2 (400×magnification). (B) Cells were treated with 50,100 or $200 \mu \mathrm{mol} / \mathrm{L}$ mangiferin for $24 \mathrm{~h}$ in dose-response studies or (C) incubated with $50 \mu \mathrm{mol} / \mathrm{L}$ MA for $0,1,4,12$, or $24 \mathrm{~h}$ in time-response studies. Total cell lysates were subjected to Western blotting with Nrf2 antibodies. $\beta$-Actin was examined as the control for equal protein loading and protein integrity. (D1) Cells were treated with $50 \mu \mathrm{mol} / \mathrm{L}$ MA for $4 \mathrm{~h}$. Subcellular expression of Nrf2 was determined by Western blotting. $\quad \beta$-Actin or lamin was examined as the control for equal protein loading and protein integrity. (D2) Nrf2 expression determined by Western blotting was quantified by densitometry. Data represented the mean \pm SD of at least three independent experiments $\left({ }^{\mathrm{b}} P<0.05\right)$. FITC, fluorescein isothiocyanate. Nrf2, NF-E2-related nuclear factors 2.

and $21.97 \% \pm 6.05 \%$ when the HL-60 cells were exposed to 1 and $2 \mu \mathrm{g} / \mathrm{mL}$ etoposide for $24 \mathrm{~h}$, respectively. However, when the cells were pre-incubated with $50 \mu \mathrm{mol} / \mathrm{L}$ mangiferin for $4 \mathrm{~h}$ prior to etoposide treatment, the apoptotic rates were $17.27 \% \pm 8.75 \%$ or $27.20 \% \pm 6.76 \%$ and were not significantly different compared to the single-agent etoposide treatment groups $(P=0.1410$ and 0.1114 , respectively).
Mangiferin relieved oxidative stress and improved cell viability in hUCB MNCs

As shown in Figure 7A1 and A2, a single treatment of mangiferin significantly reduced intracellular ROS in hUCB MNCs. Intracellular ROS were also apparently decreased when hUCB MNCs were pre-incubated with mangiferin prior to etoposide incubation in comparison to the cells incubated with etoposide alone. In addition, pre-incubation with mangiferin prior to 


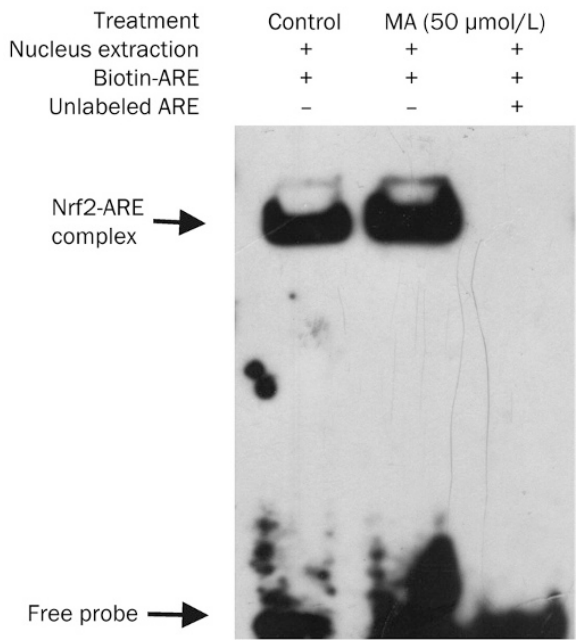

Figure 2. Mangiferin (MA) increased binding of Nrf2 with ARE in HL-60 cells. HL-60 cells were treated with $50 \mu \mathrm{mol} / \mathrm{L}$ mangiferin for $4 \mathrm{~h}$ before EMSA. Nucleus extraction was obtained and incubated with biotinlabeled ARE oligos bearing Nrf2 binding sequence (lane 2). Control cells were processed identically except for mangiferin treatment (lane 1). In competition reaction experiments, mangiferin-treated cells were also incubated with 200-fold excess of unlabeled oligos (lane 3). Nrf2, NFE2-related nuclear factors 2. ARE, antioxidant response element. EMSA, electrophoretic mobility shift assay.

etoposide incubation significantly improved hUCB MNC viability compared to incubation with etoposide alone, as shown in Figure 7B.

\section{Discussion}

The results of the present study revealed that mangiferin activated Nrf2-ARE signaling and enhanced the expression of the antioxidant enzyme NQO1 in human AML HL-60 cells. Mangiferin was also shown to relieve etoposide-induced intracellular oxidative stress. Moreover, mangiferin did not increase HL-60 cell resistance to etoposide. To date, this is the first identified natural Nrf2 activator that does not protect cancer cells against a chemotherapeutic agent.

Although mangiferin is a well-known antioxidant, the underlying signaling mechanisms are not fully understood. Nonetheless, it has been reported that mangiferin can enhance the expression of many detoxification and antioxidant enzymes, including NQO1, glutathione-S-transferase (GST), superoxide dismutase (SOD), catalase (CAT), heme oxygenase-1 (HO-1), and uridine 5'-diphosphate-glucuronosyl transferase (UDP-GT) ${ }^{[23-26]}$. Nrf2-ARE signaling is a major mechanism in the cellular defense against oxidative or electrophilic stress and controls the gene and protein expression of several types of detoxification and antioxidant enzymes ${ }^{[4]}$. However, it has not yet been documented whether mangiferin relieves oxidative stress by activating Nrf2-ARE signaling. Our results confirmed that mangiferin enhanced the accumulation of Nrf2 protein, increased the binding of Nrf2 to an ARE, and initiated the transcription of the Nrf2 target gene NQO1. These data provided the first evidence that mangiferin activates Nrf2-ARE
A

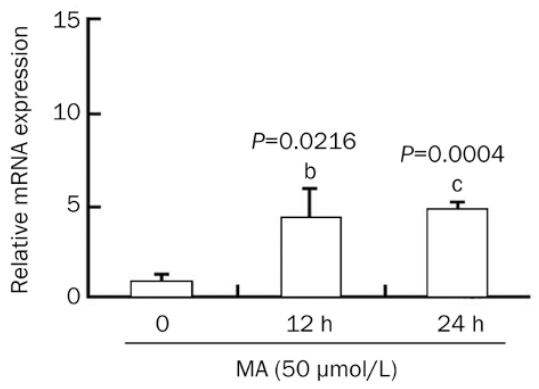

B

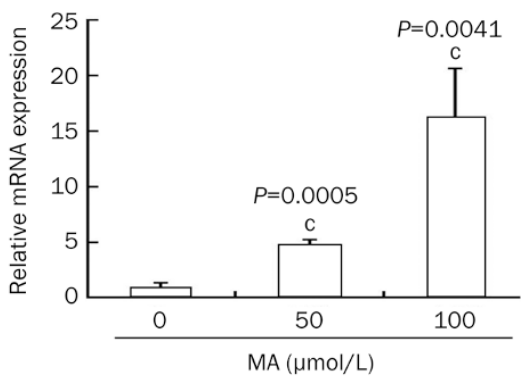

C

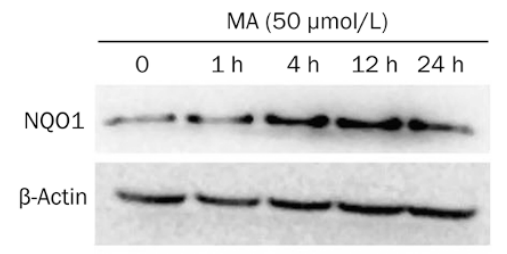

D

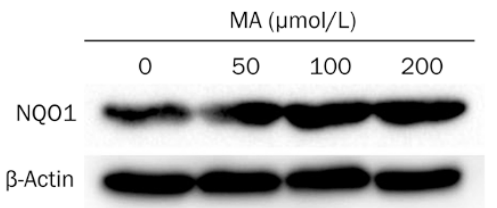

Figure 3. Mangiferin (MA) up-regulated NQO1 expression in $\mathrm{HL}-60$ cells. (A) $\mathrm{HL}-60$ cells were incubated with $50 \mu \mathrm{mol} / \mathrm{L}$ mangiferin for 0,12 , or $24 \mathrm{~h}$. Mangiferin significantly enhanced NQO1 transcription in a time-dependent manner. (B) HL-60 cells were incubated with 50 or $100 \mu \mathrm{mol} / \mathrm{L}$ mangiferin for $24 \mathrm{~h}$. Mangiferin significantly enhanced NQO1 transcription in a dosedependent manner (real-time RT-PCR). (C) HL-60 cells were incubated with $50 \mu \mathrm{mol} / \mathrm{L}$ mangiferin for $0,1,4,12$, or $24 \mathrm{~h}$. Mangiferin significantly increased NQ01 expression in a time-dependent manner in HL-60 cells (Western blot). (D) HL-60 cells were incubated with mangiferin $(0,50$, 100 , or $200 \mu \mathrm{mol} / \mathrm{L}$ ) for $24 \mathrm{~h}$. Mangiferin increased NQ01 expression in a dose-dependent manner in HL-60 cells (Western blot). Mean $\pm S D$. $n=3$. ${ }^{\mathrm{b}} P<0.05,{ }^{\mathrm{C}} P<0.01$. NQO1, NAD(P)H:quinone oxidoreductase 1.

signaling, a potential explanation for its antioxidant activity.

Chemotherapy-induced oxidative stress is recognized as a major cause of non-target tissue injury, leading to the oxidative damage of proteins (including antioxidant and energygenerating enzymes), lipids, DNA, and larger cellular components (including membranes and mitochondria) ${ }^{[1]}$. Furthermore, many preclinical and clinical studies have proved that several dietary antioxidants can reduce certain chemotherapyassociated side effects, such as doxorubicin-induced cardiotoxicity, cisplatin-induced nephrotoxicity, and bleomycin- 
A Etoposide $(\mu \mathrm{g} / \mathrm{mL})$ $\mathrm{MA}(\mu \mathrm{mol} / \mathrm{L})$
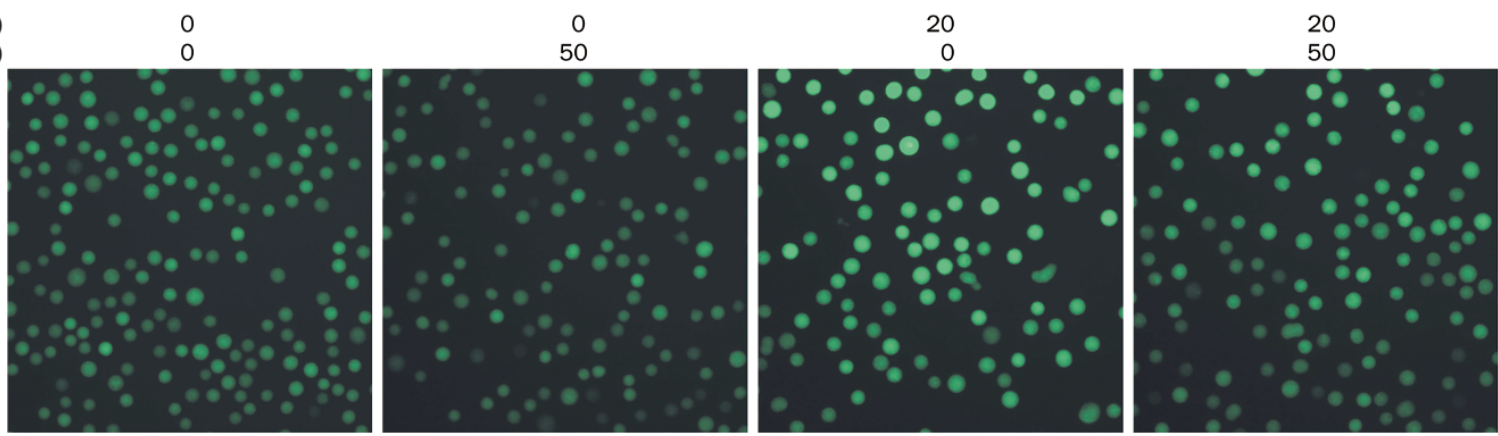

B

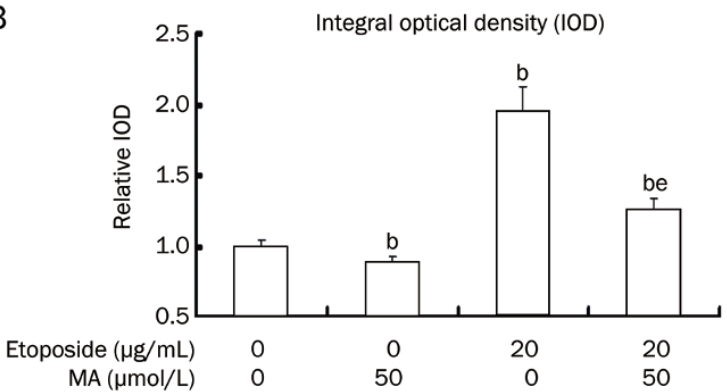

Figure 4. Mangiferin (MA) relieved oxidative stress in HL-60 cells. HL-60 cells were pre-incubated with $50 \mu$ mol/L mangiferin for $4 \mathrm{~h}$ and then treated with $20 \mu \mathrm{g} / \mathrm{mL}$ etoposide for $8 \mathrm{~h}$. Cells were loaded with $20 \mu \mathrm{mol} / \mathrm{L}$ of fluorescence probe for ROS (DCFH-DA) for $20 \mathrm{~min}$ at $37^{\circ} \mathrm{C}$. Pictures were captured using a fluorescence microscope (400xmagnification). IOD of each sample was detected by Image Pro Plus for statistics analysis ( ${ }^{\mathrm{P}} \mathrm{P}<0.05$ vs control. ${ }^{e} P<0.05$ vs etoposide treatment alone). Data represented the mean \pm SD of at least three independent experiments. ROS, reactive oxygen species. DCFH-DA , 2', 7'-Dichlorodihydrofluorescein diacetate. IOD, internal optical density.

A

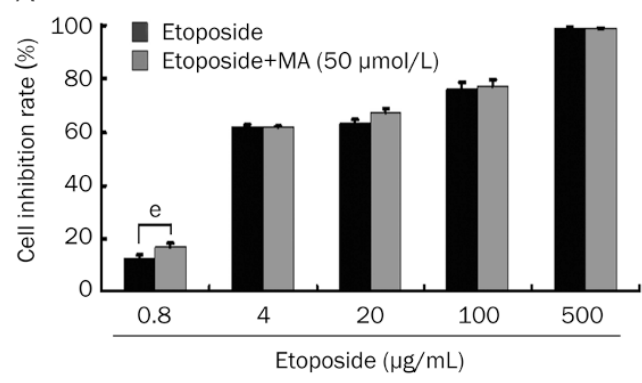

B

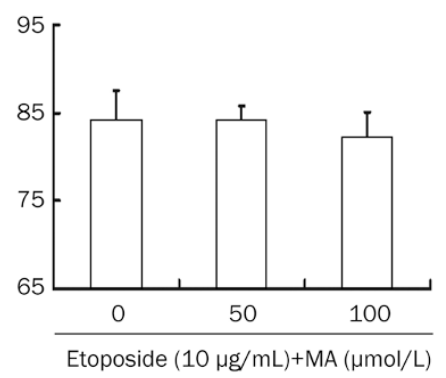

C

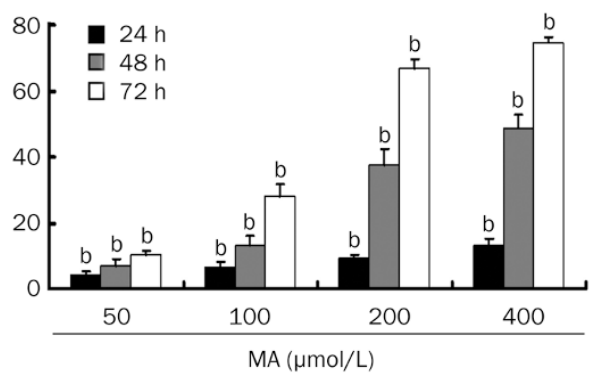

Figure 5. Mangiferin (MA) did not reduce cytotoxicity of etoposide in HL-60 cells. (A) HL-60 cells were pre-incubated with or without $50 \mu$ mol/L mangiferin for $4 \mathrm{~h}$, then treated with different concentrations of etoposide for $24 \mathrm{~h}$. (B) HL-60 cells were pre-incubated with different concentrations of mangiferin for $4 \mathrm{~h}$, then treated with $10 \mu \mathrm{g} / \mathrm{mL}$ etoposide for $8 \mathrm{~h}$. (C) HL-60 cells were incubated with different concentrations of mangiferin for 24,48 , or $72 \mathrm{~h}$. HL-60 cells without mangiferin or etoposide treatment were served as control. Cell inhibition rates were detected with MTT assay. Mean \pm SD. $n=3 .{ }^{b} P<0.05$ vs control. ${ }^{e} P<0.05$ vs etoposide alone.

induced pulmonary fibrosis, but cannot prevent certain other side effects, such as myelosuppression ${ }^{[27]}$. Interestingly, our previous work revealed that mangiferin reduced etoposideinduced DNA damage in hUCB MNCs via the activation of Nrf2-ARE signaling ${ }^{[28]}$. A frequent side effect of etoposide is myelosuppression as a result of hematopoietic cell injury. Etoposide can also cause oxidative DNA base damage, which if not repaired can lead to mutagenesis in critical genes and ultimately to such secondary malignancies as leukemia ${ }^{[29]}$. Thus, mangiferin may protect hematopoietic cells in chemotherapy, possibly reducing myelosuppression or preventing secondary leukemia, which deserves further study.

As mentioned above, a number of previous studies have shown that relieving the intracellular oxidative stress level by activating Nrf2-ARE signaling could relieve chemotherapyassociated non-target injury. However, considering the "dark side" of Nrf2 activators, there is a possibility that mangiferin could protect cancer cells against chemotherapy. Although the mechanism by which Nrf2 affects chemoresistance is not fully understood, recent studies show that Nrf2 silencing 
A
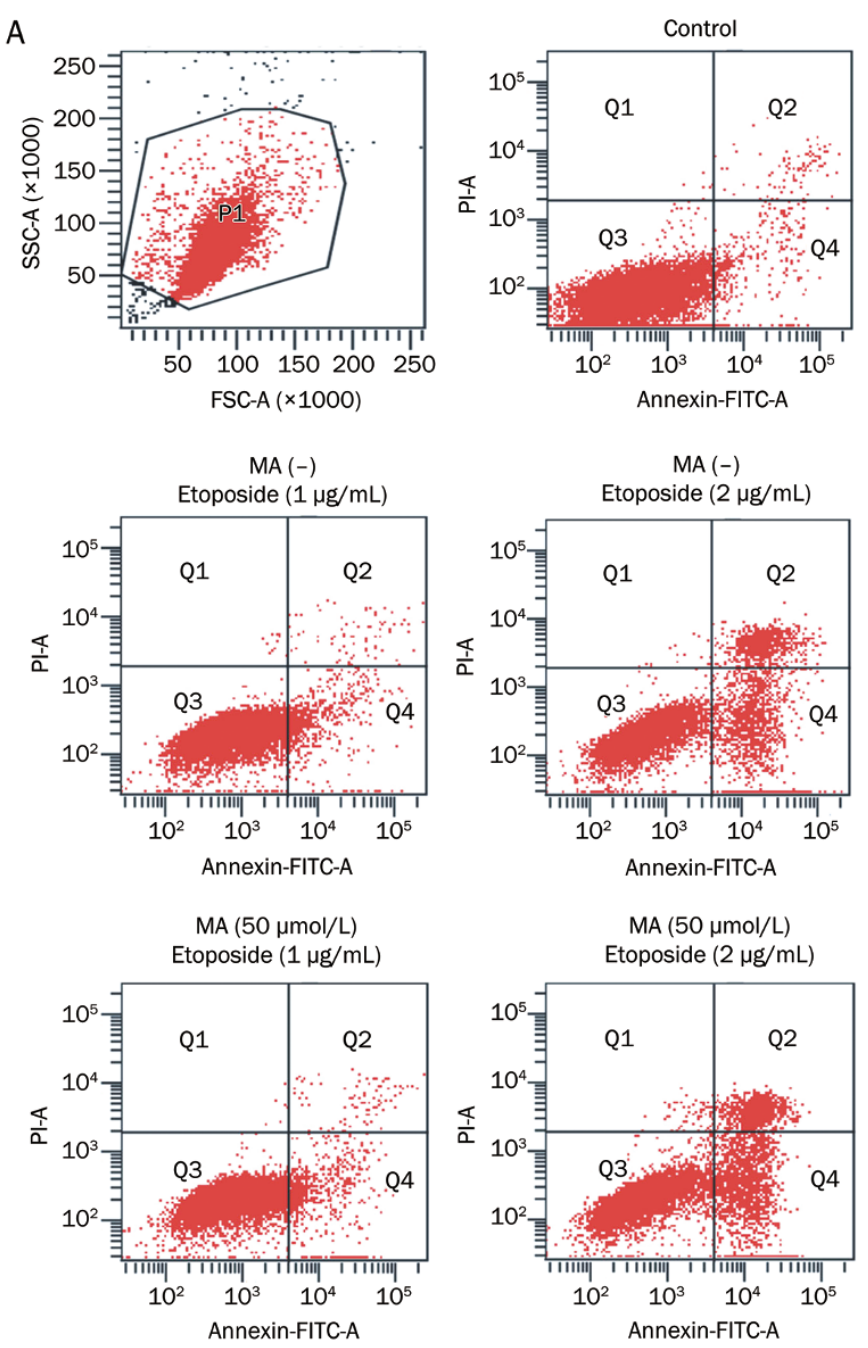

B

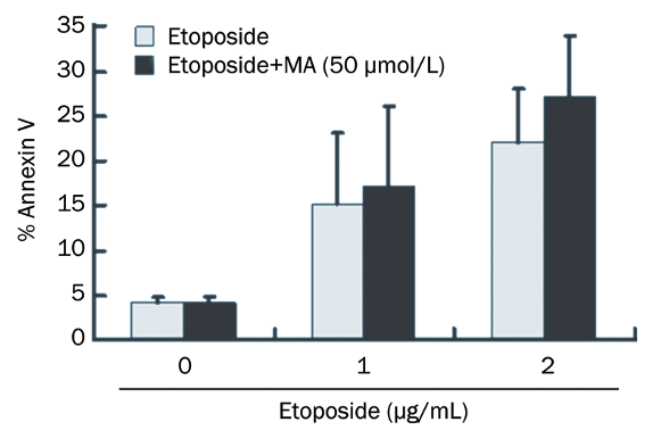

Figure 6. Mangiferin (MA) did not decrease etoposide-induced apoptosis in HL-60 cells. HL-60 cells were pre-incubated with or without 50 $\mu \mathrm{mol} / \mathrm{L}$ mangiferin for $4 \mathrm{~h}$, then treated with 1 or $2 \mu \mathrm{g} / \mathrm{mL}$ etoposide for $24 \mathrm{~h}$. Apoptotic cells were stained with FITC-Annexin $\mathrm{V}$ and detected by flow cytometry. FITC, fluorescein isothiocyanate. PI, propidium iodide. Mean \pm SD. $n=3$.

by Nrf2-siRNA enhances cisplatin-induced apoptosis and cell cycle arrest in lung cancer cell lines. These effects were considered to be associated with the down-regulation of self-defense genes, including antioxidant enzymes, phase II detoxifying enzymes, and drug efflux pumps ${ }^{[30]}$. Moreover, it was reported that Nrf2 up-regulates the expression of antiapoptotic Bcl-xL protein and reduces cellular apoptosis, and Nrf2 protein bound to an ARE (antioxidant response element) in the forward strand of the proximal Bcl-xL promoter led to increased Bcl-xL gene expression. Bcl-xL down-regulates the pro-apoptotic protein Bax and decreases caspase activity ${ }^{[31]}$. These studies suggest that Nrf2 may contribute to chemoresistance by enhancing anticancer drug metabolism, inhibiting apoptosis, or inducing the cell cycle progression in cancer cells.

Interestingly, our results demonstrate that mangiferin neither reduced sensitivity to etoposide nor inhibited etoposideinduced apoptosis in HL-60 cells, even though mangiferin increased the expression of the phase II detoxifying enzyme NQO1. The reason why mangiferin does not have this "dark side" remains unknown. One possible explanation is that, unlike other Nrf2 activators, mangiferin may have direct anticancer activity, as well as different effects on Bcl-xL in leukemia cells. It was recently reported that mangiferin induces apoptosis by reducing Bcl-xL and X-linked inhibitor of apoptosis (XIAP) expression and suppressing NF- $\mathrm{KB}$ activation in HL-60 cells ${ }^{[32]}$. NF-KB is a transcription factor that has been proven to have a critical role in cancer development and progression and to act as a major factor controlling the ability of malignant cells to resist apoptosis-based tumor-surveillance mechanisms ${ }^{[33-36]}$. The proven direct anti-tumor effect of mangiferin against breast cancer cells might be associated with the inhibition of NF-KB activity ${ }^{[34]}$. Moreover, previous studies have shown that NF-kB inhibitors can be used to overcome the resistance to chemotherapeutic agents ${ }^{[32,35,37-39]}$, and mangiferin has been shown to cause a reduction in NF- $\mathrm{kB}$ activation. Mangiferin in combination with oxaliplatin was reported to promote cell apoptosis, thereby improving the efficacy of oxaliplatin in cancer cell lines in vitro ${ }^{[33]}$. Therefore, these studies suggest that mangiferin may act as a sensitizer to anticancer drugs by inhibiting the NF-kB pathway.

Many natural flavonoids can block cell cycle progression, which contributes to their inhibitory activity in cancer cells $^{[40-42]}$. Mangiferin, a type of flavonoid, has also been reported to induce cell cycle arrest at the $\mathrm{G}_{2} / \mathrm{M}$ phase and to increase cell division cycle 2/Cyclin B1 expression in HL-60 cells $^{[43]}$. Etoposide is a cell cycle-specific anti-cancer agent that can induce apoptosis by inhibiting topoisomerase II and further causing DNA strand breakage at the $\mathrm{G}_{2}$ phase $\mathrm{e}^{[44]}$. Therefore, cell cycle arrest at the $G_{2} / M$ phase by mangiferin may contribute to the lack of impairment of etoposide-induced apoptosis and cytotoxicity by mangiferin. In conclusion, the "bright side" of mangiferin mentioned above may counteract the adverse effect as an Nrf2 activator on chemo-sensitivity, which thus masks the "dark side".

Moreover, there is another possible explanation for the lack of a mangiferin "dark side". Etoposide-induced oxidative stress can activate the p53 signaling pathway, one of its key anti-tumor mechanisms ${ }^{[45,46]}$. However, as HL-60 cells lack wild-type $p 53^{[47]}$, mangiferin cannot influence p53 activ- 
A1 Etoposide $(\mu \mathrm{g} / \mathrm{mL})$ $\mathrm{MA}(\mu \mathrm{mol} / \mathrm{L})$
0

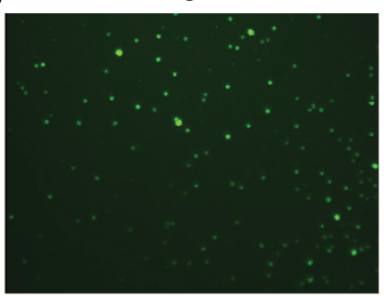

0

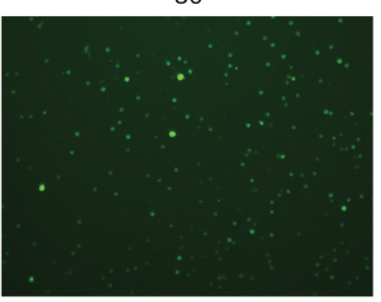

20

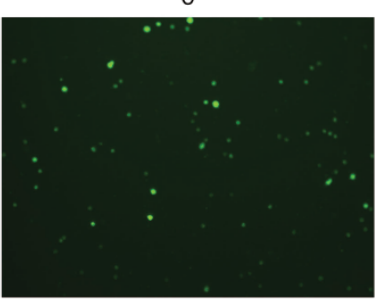

20

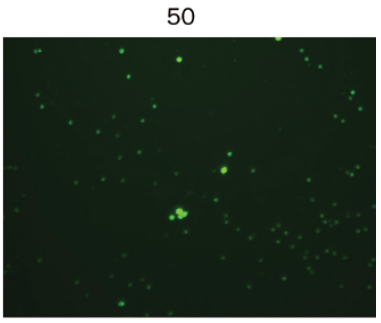

A2

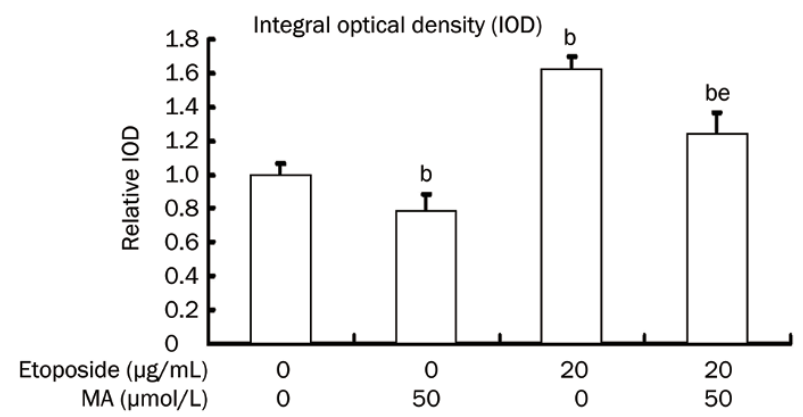

B

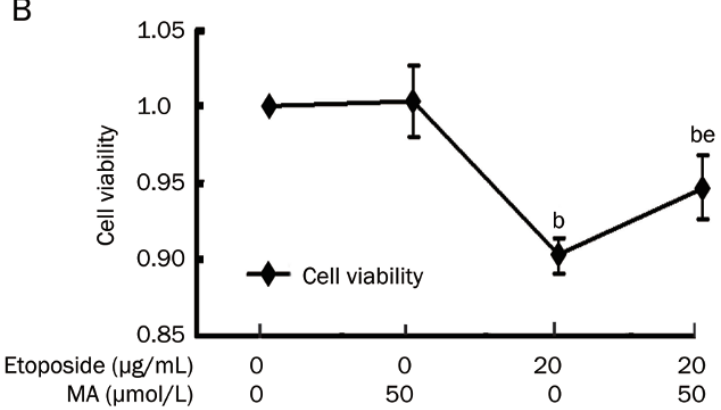

Figure 7. Mangiferin (MA) relieved oxidative stress and decreased etoposide-induced cytotoxicity in mononuclear human umbilical cord blood (MNC hUCB) cells. (A1) MNC hUCB cells were pre-incubated with $50 \mu \mathrm{mol} / \mathrm{L}$ mangiferin for $4 \mathrm{~h}$ and then treated with $20 \mu \mathrm{g} / \mathrm{mL}$ etoposide for $8 \mathrm{~h}$. Cells were loaded with $20 \mu \mathrm{mol} / \mathrm{L}$ of fluorescence probe for ROS (DCFH-DA) for $20 \mathrm{~min}$ at $37^{\circ} \mathrm{C}$. Pictures were captured using a fluorescence microscope. (A2) IOD of each sample was detected by Image Pro Plus for statistics analysis. (B) MNC hUCB cells were pre-incubated with or without $50 \mu$ mol/L mangiferin for $4 \mathrm{~h}$ and then treated with or without $20 \mu \mathrm{g} / \mathrm{mL}$ etoposide for $8 \mathrm{~h}$. MNC hUCB cells without any treatment served as control. Cell viability was detected with MTT assay. Data represented the mean \pm SD of at least three independent experiments. ${ }^{b} P<0.05$ vs control. ${ }^{e} P<0.05$ vs etoposide treatment alone. ROS, reactive oxygen species; DCFH-DA, 2',7'-Dichlorodihydrofluorescein diacetate; IOD, internal optical density.

ity, even though it activates Nrf2-mediated antioxidative responses in HL-60 cells. The lack of an effect of mangiferin on the sensitivity of HL-60 cells to etoposide may be at least partly due to the absence of wild-type p53.

In summary, the present study provides the first demonstration that mangiferin activates Nrf2-ARE signaling but does not increase resistance to anticancer drugs in human HL-60 myeloid leukemia cells. Therefore, this newly identified natural Nrf2 activator without a "dark side" may protect only normal cells and not cancer cells. Accordingly, mangiferin may provide a solution for relieving the non-target tissue injury of chemotherapy or preventing secondary malignancies, without compromising chemotherapy efficacy, possibilities that warrant further research.

\section{Acknowledgements}

This study was supported by grants from the National Natural Science Foundation of China (№ 30900632 and № 81070429 ).

\section{Author contribution}

Jun FANG and Yan CHEN initiated the project and participated in the design of the study. Ben-ping ZHANG, Jie ZHAO, Shan-shan LI, Li-jing YANG, and Ling-lan ZENG contributed to the study design and performed the experiments. Ben-ping ZHANG and Jun FANG wrote the paper. All authors contributed to the data analysis.

\section{References}

1 Chen Y, Jungsuwadee P, Vore M, Butterfield DA, St Clair DK. Collateral damage in cancer chemotherapy: oxidative stress in nontargeted tissues. Mol Interv 2007; 7: 147-56.

2 Cole M, Strair R. Acute myelogenous leukemia and myelodysplasia secondary to breast cancer treatment: case studies and literature review. Am J Med Sci 2010; 339: 36-40.

3 Azarova AM, Lyu YL, Lin CP, Tsai YC, Lau JY, Wang JC, et al. Roles of DNA topoisomerase II isozymes in chemotherapy and secondary malignancies. Proc Natl Acad Sci U S A 2007; 104: 11014-9.

4 Nguyen T, Nioi P, Pickett CB. The Nrf2-antioxidant response element signaling pathway and its activation by oxidative stress. J Biol Chem 2009; 284: 13291-5.

5 Vomhof-Dekrey EE, Picklo MJ Sr. The Nrf2-antioxidant response element pathway: a target for regulating energy metabolism. J Nutr Biochem 2012; 23: 1201-6.

6 Itoh K, Chiba T, Takahashi S, Ishii T, Igarashi K, Katoh Y, et al. An Nrf2/small Maf heterodimer mediates the induction of phase II detoxifying enzyme genes through antioxidant response elements. Biochem Biophys Res Commun 1997; 236: 313-22.

7 Li J, Johnson D, Calkins M, Wright L, Svendsen C, Johnson J. Stabilization of Nrf2 by tBHQ confers protection against oxidative stress-induced cell death in human neural stem cells. Toxicol Sci 2005; 83: 313-28.

8 Dong J, Yan D, Chen SY. Stabilization of Nrf2 protein by D3T provides protection against ethanol-induced apoptosis in PC12 cells. PLoS One 2011; 6: e16845.

9 Du Y, Villeneuve NF, Wang XJ, Sun Z, Chen W, Li J, et al. Oridonin 
confers protection against arsenic-induced toxicity through activation of the Nrf2-mediated defensive response. Environ Health Perspect 2008; 116: 1154-61.

10 Kay HY, Won Yang J, Kim TH, Lee da Y, Kang B, Ryu JH, et al. Ajoene, a stable garlic by-product, has an antioxidant effect through Nrf2mediated glutamate-cysteine ligase induction in HepG2 cells and primary hepatocytes. J Nutr 2010; 140: 1211-9.

$11 \mathrm{Hu}$ Q, Zhang DD, Wang L, Lou H, Ren D. Eriodictyol-7-O-glucoside, a novel Nrf2 activator, confers protection against cisplatin-induced toxicity. Food Chem Toxicol 2012; 50: 1927-32.

12 Kim SJ, Park C, Han AL, Youn MJ, Lee JH, Kim Y, et al. Ebselen attenuates cisplatin-induced ROS generation through Nrf2 activation in auditory cells. Hear Res 2009; 251: 70-82.

13 Yao Z, Hu W, Yin S, Huang Z, Zhu Q, Chen J, et al. 3,3'-Diindolymethane ameliorates adriamycin-induced cardiac fibrosis via activation of a BRCA1-dependent anti-oxidant pathway. Pharmacol Res 2013; 70: 139-46.

14 Kundu JK, Surh YJ. Nrf2-Keap1 signaling as a potential target for chemoprevention of inflammation-associated carcinogenesis. Pharm Res 2010; 27: 999-1013.

15 Zhao CR, Gao ZH, Qu XJ. Nrf2-ARE signaling pathway and natural products for cancer chemoprevention. Cancer Epidemiol 2010; 34: 523-33.

16 Ma X, Zhang J, Liu S, Huang Y, Chen B, Wang D. Nrf2 knockdown by shRNA inhibits tumor growth and increases efficacy of chemotherapy in cervical cancer. Cancer Chemother Pharmacol 2012; 69: 485-94.

17 Lau A, Villeneuve NF, Sun Z, Wong PK, Zhang DD. Dual roles of Nrf2 in cancer. Pharmacol Res 2008; 58: 262-70.

18 Wang XJ, Sun Z, Villeneuve NF, Zhang S, Zhao F, Li Y, et al. Nrf2 enhances resistance of cancer cells to chemotherapeutic drugs, the dark side of Nrf2. Carcinogenesis 2008; 29: 1235-43.

19 Cho JM, Manandhar S, Lee HR, Park HM, Kwak MK. Role of the Nrf2antioxidant system in cytotoxicity mediated by anticancer cisplatin: implication to cancer cell resistance. Cancer Lett 2008; 260: 96-108.

20 Yoshimi N, Matsunaga K, Katayama M, Yamada Y, Kuno T, Qiao $Z$, et al. The inhibitory effects of mangiferin, a naturally occurring glucosylxanthone, in bowel carcinogenesis of male F344 rats. Cancer Lett 2001; 163: 163-70.

21 Matkowski A, Kuss P, Goralska E, Wozniak D. Mangiferin - a bioactive xanthonoid, not only from mango and not just antioxidant. Mini Rev Med Chem 2013; 13: 439-55.

22 Chiou TJ, Tzeng WF. The roles of glutathione and antioxidant enzymes in menadione-induced oxidative stress. Toxicology 2000; 154: 75-84.

23 Viswanadh EK, Rao BN, Rao BS. Antigenotoxic effect of mangiferin and changes in antioxidant enzyme levels of Swiss albino mice treated with cadmium chloride. Hum Exp Toxicol 2010; 29: 409-18.

24 Rajendran P, Ekambaram G, Sakthisekaran D. Protective role of mangiferin against Benzo(a)pyrene induced lung carcinogenesis in experimental animals. Biol Pharm Bull 2008; 31: 1053-8.

25 Agarwala S, B NR, Mudholkar K, Bhuwania R, Satish Rao BS. Mangiferin, a dietary xanthone protects against mercury-induced toxicity in HepG2 cells. Environ Toxicol 2012; 27: 117-27.

26 Das S, Nageshwar Rao B, Satish Rao BS. Mangiferin attenuates methylmercury induced cytotoxicity against IMR-32, human neuroblastoma cells by the inhibition of oxidative stress and free radical scavenging potential. Chem Biol Interact 2011; 193: 129-40.

27 Conklin KA. Dietary antioxidants during cancer chemotherapy: impact on chemotherapeutic effectiveness and development of side effects. Nutr Cancer 2000; 37: 1-18.

28 Li S, Zhang B, Zeng L, Chen Y, Fang J. Mangiferin reduced etoposideinduced DNA damage in mononuclear human umbilical cord blood cells via activating Nrf2-mediated signaling. ASH Annual Meeting
Abstracts 2011; 118: 4626.

29 Olinski R, Jaruga P, Zastawny TH. Oxidative DNA base modifications as factors in carcinogenesis. Acta Biochim Pol 1998; 45: 561-72.

30 Homma S, Ishii Y, Morishima Y, Yamadori T, Matsuno Y, Haraguchi N, et al. Nrf2 enhances cell proliferation and resistance to anticancer drugs in human lung cancer. Clin Cancer Res 2009; 15: 3423-32.

31 Niture SK, Jaiswal AK. Nrf2-induced antiapoptotic Bcl-xL protein enhances cell survival and drug resistance. Free Radic Biol Med 2013; 57: 119-31.

32 Shoji K, Tsubaki M, Yamazoe Y, Satou T, Itoh T, Kidera Y, et al. Mangiferin induces apoptosis by suppressing Bcl-xL and XIAP expressions and nuclear entry of NF-kappaB in HL-60 cells. Arch Pharm Res 2011; 34: 469-75.

33 du Plessis-Stoman D, du Preez J, van de Venter M. Combination treatment with oxaliplatin and mangiferin causes increased apoptosis and downregulation of NFkappaB in cancer cell lines. Afr J Tradit Complement Altern Med 2011; 8: 177-84.

34 Garcia-Rivera D, Delgado R, Bougarne N, Haegeman G, Berghe WV. Gallic acid indanone and mangiferin xanthone are strong determinants of immunosuppressive anti-tumour effects of Mangifera indica L. bark in MDA-MB231 breast cancer cells. Cancer Lett 2011; 305: 21-31.

35 Nakanishi C, Toi M. Nuclear factor-kappaB inhibitors as sensitizers to anticancer drugs. Nat Rev Cancer 2005; 5: 297-309.

36 Karin M. Nuclear factor-kappaB in cancer development and progression. Nature 2006; 441: 431-6.

37 Raffoul JJ, Wang Y, Kucuk O, Forman JD, Sarkar FH, Hillman GG. Genistein inhibits radiation-induced activation of NF-kappaB in prostate cancer cells promoting apoptosis and $\mathrm{G}_{2} / \mathrm{M}$ cell cycle arrest. BMC Cancer 2006; 6: 107.

38 Xu C, Shen G, Chen C, Gelinas C, Kong AN. Suppression of NF-kappaB and NF-kappaB-regulated gene expression by sulforaphane and PEITC through IkappaBalpha, IKK pathway in human prostate cancer PC-3 cells. Oncogene 2005; 24: 4486-95.

39 Watabe M, Hishikawa K, Takayanagi A, Shimizu N, Nakaki T. Caffeic acid phenethyl ester induces apoptosis by inhibition of NFkappaB and activation of Fas in human breast cancer MCF-7 cells. J Biol Chem 2004; 279: 6017-26.

40 Hogan FS, Krishnegowda NK, Mikhailova M, Kahlenberg MS. Flavonoid, silibinin, inhibits proliferation and promotes cell-cycle arrest of human colon cancer. J Surg Res 2007; 143: 58-65.

41 Reiners JJ Jr, Clift R, Mathieu P. Suppression of cell cycle progression by flavonoids: dependence on the aryl hydrocarbon receptor. Carcinogenesis 1999; 20: 1561-6.

42 Casagrande F, Darbon JM. Effects of structurally related flavonoids on cell cycle progression of human melanoma cells: regulation of cyclindependent kinases CDK2 and CDK1. Biochem Pharmacol 2001; 61: 1205-15.

43 Yao YB, Peng ZG, Liu ZF, Yang J, Luo J. Effects of mangiferin on cell cycle status and $\mathrm{CDC} 2 /$ Cyclin $\mathrm{B} 1$ expression of $\mathrm{HL}-60$ cells. Zhong Yao Cai 2010; 33: 81-5. Chinese.

44 Hande KR. Etoposide: four decades of development of a topoisomerase II inhibitor. Eur J Cancer 1998; 34: 1514-21.

45 Brantley-Finley C, Lyle CS, Du L, Goodwin ME, Hall T, Szwedo D, et al. The JNK, ERK and p53 pathways play distinct roles in apoptosis mediated by the antitumor agents vinblastine, doxorubicin, and etoposide. Biochem Pharmacol 2003; 66: 459-69.

46 Liu D, Xu Y. p53, oxidative stress, and aging. Antioxid Redox Signal 2011; 15: 1669-78.

47 Wan CK, Wang C, Cheung HY, Yang M, Fong WF. Triptolide induces $\mathrm{Bcl}-2$ cleavage and mitochondria dependent apoptosis in p53deficient HL-60 cells. Cancer Lett 2006; 241: 31-41. 